\title{
A LÍNGUA EM SOLO BRASILEIRO NA REVISTA BRASILEITRA NO PERÍODO JK
}

\section{THE LANGUAGE IN BRAZILIAN TERRITORY IN REVISTA BRASILEIRA DURING THE JK TIME}

\author{
Vanise Medeiros ${ }^{*}$
}

RESUMO: A Revista Brasileira, que antecede e serve de palco para a fundação da $\mathrm{ABL}$, é um importante periódico brasileiro que circula na imprensa brasileira durante o governo JK. Com sua publicação suspensa desde 1948, volta a ser publicada no período em questão e apresenta alguns artigos que se debruçam sobre a língua em solo brasileiro. O objetivo neste artigo é refletir, em uma perspectiva discursiva (Auroux, Pêcheux e Orlandi), sobre a língua nos artigos que comparecem neste periódico.

PALAVRAS-CHAVE: língua, Revista Brasileira, governo JK, história das idéias lingüísticas.

\begin{abstract}
The Revista Brasileira, which precedes and sets its position as a stage for the foundation of $A B L$, was a very important periodical that circulated in the Brazilian press during JK government years. Its publication had been suspended since 1948, and it started being issued again during the specified period, introducing some articles about the language in Brazilian territory. The purpose of this article is to reflect, from a discourse-oriented perspective (Auroux, Pêcheux and Orlandi), on the language in the articles published in this periodical.

KEY WORDS: language, Revista Brasileira, JK government, history of linguistic ideas.
\end{abstract}

\footnotetext{
* Universidade Estadual do Rio de Janeiro (UERJ), Rio de Janeiro. Doutora. Professora adjunta. Email: vanisegm@yahoo.com.br.
} 



\section{A LÍNGUA EM SOLO BRASILEIRO NA REVISTA BRASILEITRA NO PERÍODO JK}

\section{Palavras iniciais}

Anos 50. Percorro os anos JK e adentro a Academia Brasileira de Letras. Como disse Orlandi (2005, p. 27), "uma das maneiras de se compreender o funcionamento do discurso sobre a língua é refletir sobre a política lingüística." Começo, então, por uma medida política de JK: o decreto no. 39.487, de 29 de junho de 1956, que incide sobre as publicações da ABL e que consta da Revista Brasileira referente a 1958 ("Notícias", 1959, p. 276). Eis seus parágrafos iniciais:

“O Presidente da República, usando da atribuição que lhe confere o art. 87, item I, da Constituição e Considerando a Lei no. 726 de 8 de dezembro de 1900, autorizando o Poder Executivo a dar instalação permanente em prédio público à Academia Brasileira e Letras, determinou que sejam impressas na Imprensa Nacional as publicações oficiais da mesma Academia e as obras dos escritores brasileiros falecidos, que ela houver reconhecido de grande valor e cuja propriedade esteja prescrita, ficando pertencendo à Nação a edição, para que se remeta parte dela à mesma Academia e às bibliotecas mantidas pela Nação e pelos Estados." (negrito meu) 
Tal decreto, como se pode ler no início do segundo parágrafo, apóia-se em outro, formulado em 8 de dezembro de 1900, referente à fundação da $\mathrm{ABL}^{1}$. Vejamos o segundo artigo do decreto fundacional:

"Art. $2^{\circ}$. Serão impressas na Imprensa Nacional as publicações oficiais da Academia e as obras de escritores brasileiros falecidos, que ela houver reconhecido de grande valor e cuja propriedade esteja prescrita.

$\$ 1^{\circ}$. A propriedade das edições referidas pertencerá à nação, devendo parte delas ser remetida à Academia e às bibliotecas mantidas pela Nação e pelos Estados." (idem)

Como se pode observar, o ato de JK não somente se apóia no decreto formulado em 1900, mas reafirma-o e lhe confere um sujeito agente: uma ordem (determinou que sejam) e um agente (na estrutura anterior, passiva sintética, não havia um sujeito agente. Em 1958 o sujeito, agora agente, é o Presidente da República) comparecem no decreto de JK. Este se articula na posição daquele que faz valer algo previsto como lei anteriormente. Faz valer um gesto inaugural da Academia. O decreto de JK faz parte de algumas medidas que retomam propostas da instauração da República, como Brasília, por exemplo. É preciso dizer algo sobre o governo JK.

Sabemos que o governo JK constrói Brasília, sabemos também que a proposta de construção de uma capital outra para o Brasil estava inscrita na primeira constituição republicana, embora não tenha sido uma idéia nascida com a República. Brasília estava, portanto, prevista naquele gesto fundacional. Mas, para além disso, Brasília funcionava como a concretização de uma antiga utopia sobre Brasil, uma utopia que habitava imaginário dos brasileiros (cf. MEDEIROS, 2003, p. 210-220). Fundar Brasília significava fundar - novamente - Brasil. No governo JK, concretizava-se no espaço territorial não somente uma nova civilização (projeto republicano), mas uma nova sociedade - o projeto de Lúcio Costa e Niemeyer implicava uma nova forma de urbanidade, e com isso se teria uma nova sociedade -, um novo homem -; a forma da cidade, sua estrutura e organização foram concebidas como instrumentos de transformação social. Ou seja, há uma movência de sentidos no período JK: para além de construir uma civilização, Brasília articulava-se à utopia de engendrar um novo homem.

\footnotetext{
${ }^{1}$ A ABL é fundada em 15 de novembro de 1896, em comemoração ao sétimo ano da República (NEVES, 1940, p. 8).
} 
A filiação do decreto de 1956 ao de 1900 não é mero recurso político. Ambos comparecem lado a lado na Revista Brasileira referente a 1958 (na parte "Notícias"). Fazem parte de uma teia que enreda governo JK e República. Pospor-se um decreto a outro, fazer valer com um decreto um outro que o antecede trabalha o espaço-tempo que os separa como tendo sido um hiato, como um espaço-tempo em suspensão, um espaço-tempo sem sentido. Dessiginifica o que houve nesse espaço-tempo, o que permite se significar como uma fundação de Brasil (cf. MEDEIROS, 2003). A ABL é uma instituição produtora de discursividade sobre língua, homem e nação. Desde sua fundação produz revista e publicações próprias. O decreto de JK incide sobre a sua produção de saber - novas publicações, que, no caso, vão dizer sobre a língua. Trata-se, pois, de uma medida política que irá trabalhar o imaginário lingüístico, e este, como se sabe em análise de discurso, não se separa do sujeito.

O objetivo deste trabalho é refletir sobre a língua em um importante periódico nacional, qual seja, a Revista Brasileira. Revista que antecede à $\mathrm{ABL}$, que passa a ser publicação da $\mathrm{ABL}$ em momento posterior e que volta a ser publicada no período JK. A reflexão a ser aqui promovida tem como suporte teórico duas áreas de conhecimento, a saber, a Análise de Discurso (PÊCHEUX e ORLANDI) e a Epistemologia dos Estudos de Linguagem (AUROUX).

\section{Palavras sobre a revista brasileira}

No Brasil, grosso modo, as revistas brasileiras surgem em decorrência das instituições (cf. MARIANI e MEDEIROS, 2006). Não é, contudo, o que ocorre com a Revista Brasileira. Ao contrário, há aí uma inversão. Fundada em 1895 por José Veríssimo substituindo a revista A Semana, fruto de um grupo de intelectuais nos primeiros anos da República, é na reunião da redação da Revista Brasileira que se apresenta novamente a idéia da fundação de uma Academia Brasileira de Letras e que se a efetiva (inclusive a redação da Revista serviu de sede à Academia). Se em sua redação nasce a $\mathrm{ABL}$, a Revista Brasileira não se configura, de início, como revista da Academia. Nos estatutos iniciais da ABL, consta a publicação de revista própria - Revista da ABL. É somente em 1941, sob a presidência de Levi Carneiro, que passam a ser publicadas pela ABL duas revistas: a Revista Brasileira e Revista da $A B L$.

É preciso dizer que a incorporação da Revista Brasileira à Academia não se faz sem uma polêmica sobre a divisão do espaço dos intelectuais e 
acadêmicos e de suas produções. A possibilidade de uma outra publicação - que passa a constar do estatuto de 1951 - pela Academia instaura três posições. Uma, encabeçada por Levi Carneiro, presidente da Academia, que pensava a Revista Brasileira como destinada a produções de escritores que não fizessem parte da Academia e a Revista da $A B L$ voltada para a produção dos acadêmicos; outra, por Ribeiro Couto, que propunha a Revista Brasileira como restrita à literatura, ao passo que toda matéria outra oriunda da Academia fosse para o corpo da Revista da ABL. Portanto, uma opunha produção acadêmica à não-acadêmica; outra, produção literária à não-literária. A proposta vencedora não foi, no entanto, uma das duas, mas uma terceira, a de Roquete Pinto: a Revista Brasileira publicaria artigos inéditos de acadêmicos e não-acadêmicos, os primeiros não seriam, contudo, remunerados, e a Revista da $A B L$ diria respeito às coisas da Academia (atas, discursos, artigos, notícias, entre outras coisas). O efeito que se observa dessa divisão é que a Revista Brasileira passa a ter seu funcionamento como revista de artigos; já a Revista da $A B L$, embora agora denominada revista, continua a funcionar como Anais da ABL. É interessante notar que do verbete "revistas" de Coutinho (2001) não consta a segunda; esta só comparece no verbete "Academia Brasileira de Letras" (COUTINHO, 2001, p. 149-152). Como um apêndice e não com vida própria, como é o caso da Revista Brasileira.

De publicação irregular, e após 10 anos sem ser publicada (deixou de ser editada em 1948), a Revista Brasileira volta a circular no governo JK. São quatro os seus números durante tal período: dois referentes ao ano de 1958 (um deles, publicado em 1959), dois referentes ao ano de 1959 (um deles publicado em 1960). Em 1960, há uma nova interrupção. Retomando a polêmica acima exposta, cabe observar que, se a proposta de Roquete Pinto se apresenta como apagando a oposição produção literária versus produção não-literária, a Revista Brasileira é, no entanto, apontada como tendo perfil literário (assim comparece em diversos lugares). E seu corpo denuncia tal atribuição. Ela se divide em duas partes: uma, em que constam poemas, contos e artigos (muitos literários); outra, menor, denominada "notícias", em que se acham notícias que podem ser da revista, de colaboradores, de fora da Academia e das publicações recebidas. Nos quatro números do governo $\mathrm{JK}$, encontram-se quatro artigos que tratam de questões referentes à língua. São artigos de filólogos não pertencentes à Academia (dois artigos de Tenório d'Albuquerque e dois de Julio Nogueira). 
Acerca dos filólogos, podemos dizer que é aquele que mais do que saber a língua tem um reconhecimento por um saber sobre a língua. Diferentemente do literato, reconhecido por trabalhar a língua, ao filólogo é dado o lugar de autoridade sobre a língua, é aquele que irá dizer da língua (e, nesse sentido, irá dizer da língua que o literato trabalha). Portanto, é aquele a quem se confere o papel de "legislador" da língua. Pensando discursivamente, ocupa um lugar de sujeito da gramatização². Com Guimarães (1996, p. 128), observamos que a gramatização brasileira do português se dá a partir dos anos 80 do século XIX. A ABL é fruto deste período de gramatização do brasileiro. No que tange à relação filólogo e ABL, cabe observar que esta não os contemplava em seus quadros ${ }^{3}$ : não só poucos eram os acadêmicos que se destinavam a estudos filológicos como também, em geral, eram rejeitadas as suas candidaturas à Academia (o que também é caso, mais tarde, de Julio Nogueira, um dos autores dos artigos em foco). O filólogo, portanto, não pertencia à $\mathrm{ABL}$ (daí estes terem se reunido para formar a Academia dos Filólogos) e, no período JK, ainda a ela não pertence ${ }^{4}$ (cf. HENRIQUES, 2001, p. 23): são chamados quando seus trabalhos se fazem necessários. É, pois, deste lugar de tensão - do reconhecimento de um saber sobre a língua e do não-pertencimento à Academia - que são assinados os quatro artigos, a saber: "Novos idiomas? Não!" e "O português em Portugal e no Brasil: sobrevivência de palavras e construções", ambos por Tenório d’Albuquerque; "Em defesa da língua" e "A língua falada", por Julio Nogueira.

\footnotetext{
${ }^{2}$ Por gramatização, "deve-se entender o processo que conduz a descrever e instrumentar uma língua na base de duas tecnologias, que são ainda hoje os pilares de nosso saber metalingüístico: a gramática e o dicionário." (Auroux, 1992, p. 65). Aqui, também está se retomando Orlandi (2002, p. 191-202) quando esta aponta que, no processo de gramatização do brasileiro (ORLANDI, 2002, p. 191-202) comparecem literatos, gramáticos e filólogos. Embora seja tênue a fronteira entre filólogos e gramáticos (nem sempre gramáticos são considerados filólogos e vice-versa, ainda neste período), em relação à língua são três lugares distintos. Talvez possamos, a partir de Orlandi, pensar o literato como aquele que trabalha a língua, o gramático como aquele que, ao produzir gramáticas, dá contornos a língua, desenha-a, estabiliza-a, estabelece seus limites, e o filólogo como aquele que produz a investigação que a torna legítima, que escava a língua para, assim, conferir-lhe ou não legitimidade.

${ }^{3}$ Embora o primeiro trabalho da Academia tenha sido referente à lexicografia, isto é, sobre a grafia da palavra Brasil.

${ }^{4}$ Conforme Henriques (2001, p. 23), esta é uma prática ainda recorrente. Nos últimos quarenta anos, somente quatro filólogos ocuparam cadeiras na Academia, a saber: Aurélio Buarque de Holanda, Abgar Renault, Antonio Houaiss, Celso Cunha.
} 


\section{Palavras sobre a tensa especificidade da língua em solo brasileiro}

As questões que norteiam este artigo são: como significam a língua que aqui se faz presente? Como se posicionam frente à questão da língua que comparece em solo brasileiro? O que dizem dessa língua?

Os títulos dos artigos da Revista Brasileira intrigam e instigam, por exemplo: "Novos idiomas? Não!" e "Em defesa da língua”. Que novo idioma? Defesa de que língua? Ambos inscrevem uma alteridade com a pergunta seguida de resposta - no primeiro caso - e com a palavra "defesa" - no segundo caso: contra quem ou o quê?

O artigo “Novos idiomas? Não!", de Tenório d’Albuquerque, se abre com citações em francês seguidas de quatro outras em português que apontam e atestam a dialetação das línguas: as línguas se partem em outras, recupera-se em Meillet. As línguas se partem - acréscimo e deslize - em dialetos, busca-se em Dauzat. A língua que comparece em solo brasileiro, vai dizer então Tenório d'Albuquerque, é produto de dialetação. Responder, pois, à pergunta "Novos idiomas?" significa dizer não há "língua brasileira":

"Evidentemente discordamos dos que pretendem fabricar línguas na América e outras infantilidades semelhantes. É inadmissível falar-se em Língua argentina ou em Língua brasileira,..." (TENÓRIO D’ALBUQUERQUE, 1959, p. 177) (negrito meu)

Há dialetação. Estamos em um momento posterior à polêmica sobre que nome dar à língua que se fala em solo nacional, momento posterior à denominação da língua em solo brasileiro como língua portuguesa (DIAS, 2001, p. 185-197). Ambos, Tenório d'Albuquerque e Julio Nogueira, se opõem à denominação "língua brasileira"5; e ambos afirmam a especificidade da língua que aqui se verifica. A questão então é entender como se articula em seus textos a tensão entre especificidade da e na língua em território brasileiro (falada e também escrita) e a unidade: língua portuguesa. Tensão que vai dizer do e para o sujeito nacional, que vai trabalhar lugares e formas de identificação do brasileiro. Compreender esta tensão, tarefa do analista, implica analisar aqui o funcio-

${ }^{5}$ Julio Nogueira participou da comissão que nomeia a língua nacional como "língua portuguesa”. 
namento da diferença, ou melhor, investigar como vai significando a especificidade.

Nos quatro artigos, a diferença em solo brasileiro é apontada na língua falada e em diversos lugares da língua escrita. A especificidade se encontraria na pronúncia (na prosódia, no acento fraseológico) e no léxico. Embora tratem de casos em que a especificidade se verifica na sintaxe, este não é um espaço referido como da diferença. Em outras palavras, não silenciam a sintaxe, mas negam à sintaxe um lugar de especificidade. Orlandi, em Formas do silêncio, vai falar da "força corrosiva do silêncio, que faz significar em outros lugares o que não "vinga" em um lugar determinado." (1997, p. 13). Julgo que negar aqui tem um importante funcionamento: faz significar, ou, ao menos, funciona na pretensão de conferir sentido. Negase, pois, que na sintaxe brasileira ocorram diferenças de valor: se existem, ou são de pormenor ou são deturpações; não alteram o idioma. Nega-se a língua brasileira. E isto produz sentido, tem efeitos. Um deles é sustentar um imaginário de língua una: “a estrutura é uma só, para o português de Portugal e do Brasil” (TENÓRIO D’ALBUQUERQUE, 1959, p. 177); um outro, decorrente deste, é colocar a diferença de ordem sintática no lugar do erro a ser corrigido. Um terceiro é permitir a especificidade: esta não é estrutural (ainda que, como sabemos, o acento fraseológico tenha impacto na sintaxe). Indo mais adiante, a negação da diferença de ordem sintática permite que se conjugue o binômio que articula a defesa da diferença - a especificidade do português no Brasil - e a afirmação da unidade (língua portuguesa). Defesa que nesse momento significa "ser nacionalista", que permite a oposição a gramáticos portugueses - vozes convocadas - que se negam a "reconhecer a evolução do português no Brasil" (TENÓRIO D’ALBUQUERQUE, 1959), sem, no entanto, que se saia da mesma formação discursiva ${ }^{6}$ que agasalha ambas as posições. Continuemos com os artigos, para melhor entender o desenho dessas posições e o contorno da formação discursiva que as significam.

"Em defesa da língua" é um artigo de Julio Nogueira. Diante de tal título, a pergunta imediata é, como exposto anteriormente, defesa de que língua? O autor nos responde: “(...) nosso intuito principal, que é a defesa da língua

${ }^{6}$ Pêcheux (1988, p. 160) define formação discursiva como "aquilo que, numa formação ideológica dada, isto é, a partir de uma posição dada numa conjuntura dada, determinada pelo estado da luta de classes, determina o que pode e deve ser dito (articulado sob a forma de arenga, de um sermão, de um panfleto, de uma exposição, de um programa etc.)”. 
que falamos..." (NOGUEIRA, 1959, p. 162). Então parece tratar-se da defesa da língua falada. Cabe registrar que o outro artigo deste mesmo autor na Revista brasileira denomina-se "Língua falada". Ambos os artigos se articulam em um "eixo enunciativo", isto é, ambos compõem uma posição homogênea. A pergunta agora é: como a língua falada aí comparece? O que se diz sobre ela?

Em primeiro lugar, marca-se a diferença: pontua-se que Brasil e Portugal falam diferentemente.

"O cinema português, apesar de excelente, não foi muito bem sucedido no Brasil, porque a massa da população não entendia o que diziam os personagens da fita." (NOGUEIRA, 1960, p. 102)

Para além da não-compreensão, defende-se o direito à diferença.

"Quando chegamos ao Rio, pela primeira vez, por 1912, causou-nos impressão desagradável notar que artistas brasileiros, no palco, falavam com sotaque lusitano. Explicaram-nos que era para não desafinar... Naquele tempo, o elenco das companhias, na maioria, se compunha de artistas portugueses. A razão não nos pareceu boa. Mais óbvio seria que os artistas lusitanos procurassem acomodarse à fala brasileira, pois brasileiro era o auditório e, às vezes, a peça. (...) Mas o tempo exerceu a sua ação natural e os palcos se foram aos poucos abrasileirando. (NOGUEIRA, 1960, p. 103)

As diferenças, portanto, existem e se situam, como já dito, na pronúncia e no léxico. Comecemos pela pronúncia. No artigo de Nogueira, "A língua falada", são apresentados quatro casos de pronúncia: dois seriam corretos e dois, incorretos. É interessante pensar aí como funciona a questão, presente nos artigos, sobre a mudança das línguas. Nesse material discursivo da Revista brasileira, a língua vai ser explicada como fato social e como passível de mudanças ao longo dos tempos. Isto funciona como justificativa para a especificidade do brasileiro frente ao falar português. No entanto, nem toda diferença é apontada como legítima. Dito de outra maneira, o que vai sendo significado é que as línguas mudam, mas nem tudo o que nelas ocorre é mudança. Esta é a

${ }^{7}$ Conforme Pfeiffer (2001, p. 169), o eixo enunciativo: "constitui-se de várias enunciações que vêm de um mesmo lugar discursivo. Esta categoria não pode ser confundida ou tomada pela noção de formação discursiva: em uma mesma formação discursiva concorrem vários 'eixos enunciativos"'. 
tensão: separa-se o que seria da ordem da mudança do que seria da ordem da corrupção. A questão da especificidade do português se articula, então, entre a legitimação da mudança e a condenação daquilo que não seria mudança, mas deturpação. Em outras palavras, a noção de mudança só irá se aplicar aos casos de acerto. Estes constituíram mudanças em relação ao falar português; e o que os significa como tal é o aval tanto da literatura portuguesa (em geral, escritores portugueses arcaicos) quanto de vocabulários ortográficos brasileiros. Os outros casos, sem este tipo de aval, não constituiriam mudanças. Seriam, jogando com as palavras Nogueira, palavras que não existem.

Algumas são as observações a serem feitas. Uma primeira diz respeito à posição do brasileiro: este já legisla sobre a língua que aqui se fala (cf. ORLANDI, 2002, p. 191-203). Uma outra decorre do lugar de ocorrência dos acertos - mudanças - e dos erros - deturpações. Estes se verificariam tanto em Portugal quanto no Brasil. E, no caso do Brasil, os erros são apontados como advindos de pessoas não cultas, dos rádios e da tv - em geral, das radio e telenovelas que emergem neste período e de seus locutores. Denuncia-se então o que seria o falar popular e a popularização da língua pelos meios de comunicação em evidência no período. Desloca-se, com isso, a diferença geográfica (Brasil versus Portugal) para a diferença social: agora a oposição se verifica entre um falar culto e um falar popular. Uma das conseqüências deste descolamento é que a pronúncia deve ser ensinada nas escolas (consta dos livros e deve fazer parte das aulas, NOGUEIRA, 1959). Um dos efeitos de tal deslocamento é a manutenção, agora social, da "ideologia do déficit” de que tratou Mariani (2004, p. 25).

Há ainda uma outra observação a ser feita. Nesses artigos da Revista Brasileira, portugueses e brasileiros são postos lado a lado: ambos erram e acertam $^{8}$ a língua. Mas são lugares distintos e assimétricos:

"Sempre abrimos aos portugueses um largo crédito por nos terem dado uma língua rica, numerosa, capaz de exprimir todos os sentimentos, língua que se tornou a matéria prima de excelsos artistas, a princípio sòmente portuguêses e, depois, portugueses e brasileiros(...) Foi um presente régio, um tesouro que soubemos não só conservar, mas ainda enriquecer de novos e produtivos recursos." (NOGUEIRA,1960, p. 104) (negrito meu)

\footnotetext{
${ }^{8}$ Em que um dos sentidos de acertar é também atingir a língua.

${ }^{9}$ Foi mantida a ortografia da época (o que ocorrerá nas outras seqüências discursivas do
} 
O lugar do português é aquele de quem deu um "presente régio"; o do brasileiro é aquele de quem recebe, de quem é grato, mas também de quem sabe conservar e... enriquecer. É sobre este "enriquecimento" que pretendo tratar agora. Onde reside? Como funciona?

De imediato é preciso dizer que, no material discursivo da Revista Brasileira, o enriquecimento tem um lugar específico na língua: o léxico. É aí que se verificaria o que seria a contribuição brasileira ao idioma português. Mas de que léxico trata a Revista Brasileira? Espaço de dissensões ao longo da nossa história (como demonstram Mariani, 2006, e Nunes, 2006), na Revista Brasileira, o léxico brasileiro significa na formação discursiva que propõe o idioma português como instância superior às diferenças entre Brasil e Portugal. É preciso explicar, mas, para isso, é necessário recuperar as alteridades que se inscrevem nessa materialidade lingüística.

Algumas são as vozes que comparecem nos artigos; por exemplo, vozes estrangeiras que legitimam e dão sentido ao dizer. Essas não constituem uma posição discursiva em relação à língua que no Brasil se apresenta, embora permitam deslizamentos que a posição discursiva autoral - aquela que assume o dizer e por ele se responsabiliza - pretenda conter (mas isto é uma outra história). São quatro as posições discursivas que comparecem nos artigos em foco: três na voz do brasileiro, uma na voz do português. Abaixo se encontra um quadro que pretende ajudar na exposição dos contornos dessas posições:

De imediato, como podemos notar, as três das posições do brasileiro se opõem à posição do português no que tange à especificidade da língua que comparece em solo brasileiro: há diferenças, dizem os brasileiros, e, para a segunda posição, são significativas. Não há divergências, não há dialetação, não há especificidade no que aqui ocorre, dizem os portugueses. Poderíamos talvez pensar com isso em duas formações discursivas: a que fala da especificidade e a que se opõe à especificidade. Não julgo ser este o caso da materialidade discursiva de que trato. Um olhar mais atento ao quadro nos mostra uma instância outra - idioma português - redesenhando posições brasileiras e portuguesas.

As posições brasileiras ( 1 e 2), como já se notou, defendem a especificidade, opondo-se assim à posição portuguesa. No entanto, nestas

corpus deste trabalho). 
duas posições do brasileiro (posição 1 e 2), as diferenças se verificam tanto no falar do brasileiro quanto no falar do português, ou seja, tanto em solo brasileiro quanto em solo português. O ambiente é um argumento convocado para a mudança das línguas. Observem-se as seqüências abaixo:

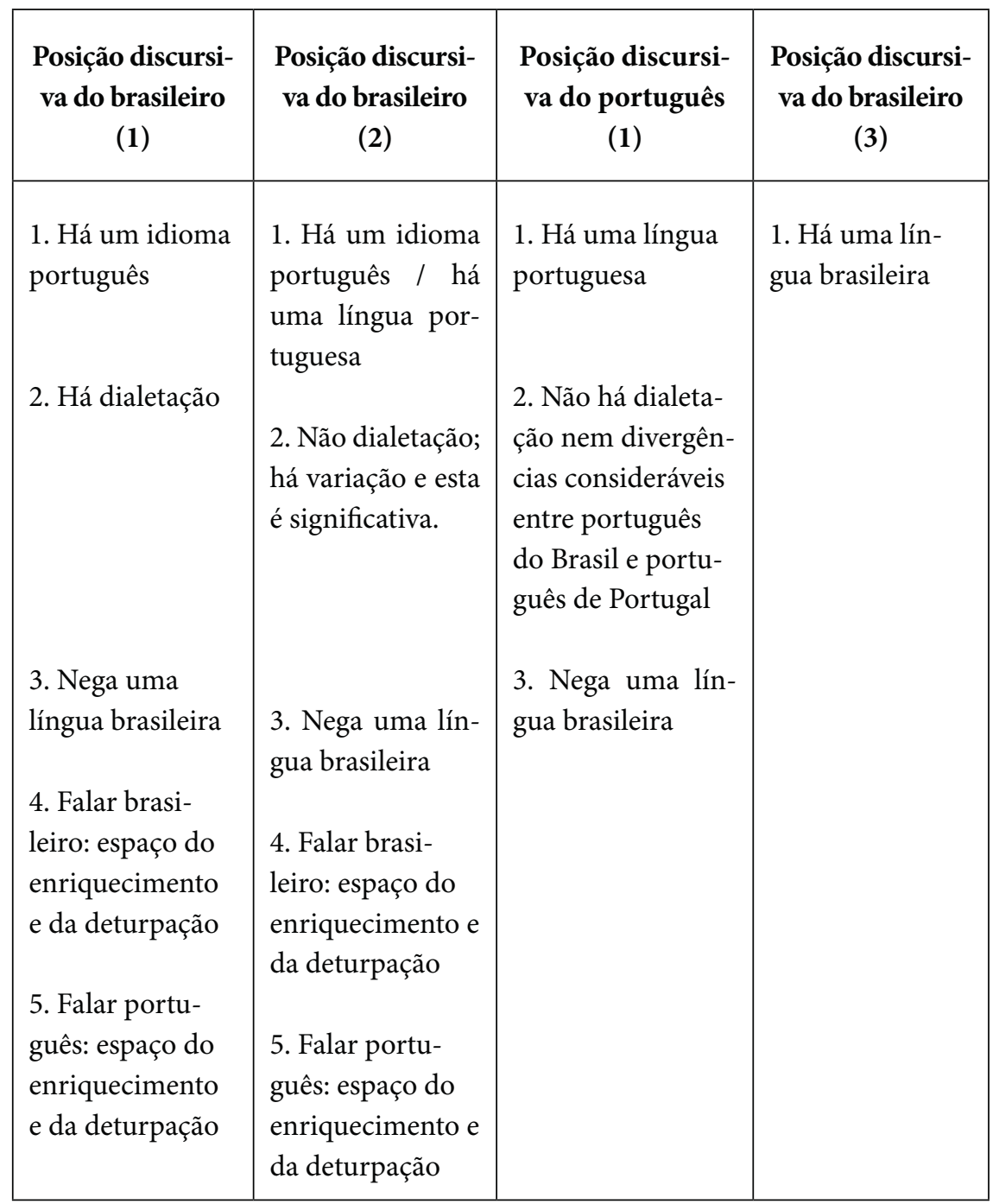


"Respondam os que negam a existência de sensíveis divergências entre o português de Portugal e o do Brasil e entre o castelhano da Espanha e o que é falado nas Américas.

É absurdo pretender-se uniformidade rigorosa entre o castelhano da Espanha e o da Argentina, do Chile, da Colômbia, do Equador, do Peru, do México, da Venezuela etc. São diversos os ambientes. Os fatores atuantes não são os mesmos, logo os resultados não podem ser iguais.

(...) princípios fundamentais, cientificamente estabelecidos.

É incontestável a influência dos ambientes com sua complexidade de fatores como clima, contacto com outras línguas distintas, condições de vida, etc." (TENÓRIO D’ALBUQUERQUE, 1959, p. 171) (negrito meu)

"Se os espanhóis admitem a existência de vários dialetos na Espanha, se os portugueses aceitam a existência de dialetos em Portugal, por que incoerentemente se negam, com obstinação, a aceitar igual fenômeno na América, com uma área territorial incomparàvelmente maior, com uma população várias vezes superior às das antigas metrópoles?

(...) por que negam a existência de dialetos no Brasil (...)?”(idem) (negrito meu)

"A história das línguas confirma que o próprio erro constitui elemento de composição delas. (...) Se divergências se apresentam dentro do mesmo clima em que a língua nasceu e se emplumou, que se pode esperar de uma língua de importação, como o português, em relação ao Brasil”. (NOGUEIRA, 1960, p. 101) (negrito meu)

Não se pode negar a mudança é o que diz a posição brasileira à posição portuguesa, afinal, ela é produto do espaço geográfico, como atestam "princípios cientificamente estabelecidos". Até o erro é produto da história da língua. E, para além disso, tanto o falar do brasileiro quanto o português apresentam-se como espaço de enriquecimento e de deturpações. Igualam-se diante de algo que os ultrapassa: um idioma comum. Estamos, pois, diante de duas formações discursivas: uma, que postula a existência de um idioma português, que agasalha o que ocorre tanto em solo português quanto em solo brasileiro; outra, que postula a existência de uma língua brasileira.

No caso desta segunda formação discursiva, não se trata de uma diferença que trabalhe uma relação de dependência entre formas de ocorrência 
de uma língua, trata-se de postular uma outra língua, o que implica outra história, ou ainda, de romper com o que seria a "tradição portuguesa”. Ainda em relação a esta formação discursiva, é interessante observar que ela se apresenta como alteridade inscrita - e rejeitada - nos títulos de dois artigos: "Novo idioma? Não!" e "Em defesa da língua". Em que a defesa da língua não significa a defesa da língua falada no Brasil frente a Portugal, como poderíamos pensar a princípio, mas defesa da "boa e sã linguagem portuguesa" (NOGUEIRA, 1959), que, tanto lá como cá, contém "novidades" que constituem problemas ${ }^{10}$. Erram brasileiros e portugueses. O título "Em defesa da língua" é sintomático de uma posição que coloca o que aqui se fala como filiado a Portugal, como decorrente da língua portuguesa - mesmo no que tange à diferença (veremos isto ao tratarmos de brasileirismos mais adiante) - e por ela justificada.

Então, a primeira formação discursiva - matriz de sentido dos artigos em foco da Revista Brasileira que tocam a língua que aqui se verifica - acolhe tanto aqueles que apontam a posição discursiva que postula a especificidade do brasileiro - que seria da ordem de uma variação ou dialetação, mas não da ordem de uma língua (o que compreende duas posições, conforme exposto no quadro já apresentado) - quanto uma posição antagônica a esta, isto é, a posição dos que não postulam tal especificidade - no caso, a dos portugueses. Todas reafirmando a supremacia da língua portuguesa. Sobre tal formação poderíamos dizer, jogando com as palavras de Orlandi, que se fala em um outro lugar, que se fala diferente, mas que se fala o mesmo.

Disse que o ambiente justifica a mudança, disse também que o apagamento da diferença sintática produz um deslocamento do geográfico para o social. Disse ainda que a especificidade do léxico brasileiro tem espaço na formação discursiva que postula o idioma português. É hora de observar como isto funciona.

\section{Palavras sobre os brasileirismos na revista brasileira}

Conforme Orlandi (1990), a história do Brasil não se fez sem a recolha de um léxico que aqui existia. No século XIX, e, sobretudo, no início do século $\mathrm{XX}$, há uma intensa produção de dicionários e de vocabulários (Nunes,

\footnotetext{
${ }^{10}$ No artigo "Em defesa da língua” de Nogueira (1959) são apresentadas algumas "novidades" (mais exatamente seis), algumas no Brasil e outras em Portugal, que constituem problemas a serem extirpados da língua portuguesa.
} 
2005, p. 43-44) que, de uma forma ou de outra, vai trabalhando um léxico que corre em terras brasileiras e o vai significando como brasileirismos, regionalismos, barbarismos, por exemplo. Várias são as denominações e vários os seus sentidos. Neste artigo, vou me ater a uma denominação brasileirismos - para pensar no léxico. O que são brasileirismos na Revista Brasileira do período JK?

São diversos os sentidos de brasileirismo nos séculos XIX e XX. Para citar um exemplo, de acordo com Mariani (1994, 43-53), no espaço polêmico no século XIX em torno de um imaginário de língua, uma das formações discursivas, a dos gramáticos e eruditos, entendia como "brasileirismos" tanto palavras de origem tupi quanto de origem africana. Estes brasileirismos (então, africanismos e indianismos) resultavam em corrupção lingüística; ou seja, entravam nas gramáticas como desvios, formas a serem evitadas. Tal polêmica adentra o século XX com os inúmeros dicionários e vocabulários aí construídos. Não se pode deixar de recuperar que é do final do século XIX a ABL. Esta se propõe, na sua fundação, como uma de suas funções, a organizar um vocabulário crítico dos brasileirismos. Em, 1910, brasileirismos começam a ser coletados. Tal projeto, do que seria um grande dicionário de brasileirismos, vai, no entanto, mudando ao longo dos anos. Ainda em 1910, em lugar de se ter um dicionário de brasileirismos é proposto um dicionário etimológico e histórico da língua portuguesa. Institui-se uma comissão de lexicógrafos para tal finalidade. Mas este não chega ao fim. Outras mudanças e propostas ocorrem. É somente em 1956, com o decreto de JK, apontado no início, que um dicionário da Academia, com cem mil verbetes, e com nome de Antenor Nascentes, é enviado para publicação. Desaparece o termo "brasileirismo" e tem-se, aí, ressaltada como inovação, a transcrição fonética ${ }^{11}$. Não é o caso agora refletir sobre percurso deste dicionário tampouco perseguir os sentidos de brasileirismo nas diversas propostas que se apresentaram à Academia ao longo destes anos. Importa destacar, por ora, a tensão na denominação "brasileirismo" e seu apagamento no título do dicionário que se imprime pela Academia e como sendo da Academia. A proposta agora é observar os sentidos de brasileirismo na Revista Brasileira, revista da Academia em um momento em que o dicionário da Academia vai para a gráfica. Tomemos algumas seqüências

\footnotetext{
${ }^{11}$ Importa destacar que a inserção da transcrição fonética ocorre em um momento em que a pronúncia da língua falada está em questão.
} 
discursivas dos artigos em foco:

"Na sintaxe, são diminutas as divergências mas no vocabulário é, bastante apreciável, a transformação assinalada aqui. Ademais no enriquecimento do léxico, com a contribuição de milhares de palavras oriundas das línguas indígenas, temos a conservação, na América, de vocábulos já em desuso no Europa, significações novas atribuídas a palavras ainda correntias na península Ibérica, formação de novos diminutivos, em suma,..." (TENÓRIO D’ALBUQUERQUE, 1959, p. 170)

Indianismos, arcaísmos e antigos vocábulos com novas significações enriquecem a língua portuguesa. Uma primeira observação diz respeito aos indianismos: corrupção em uma certa formação discursiva no século XIX, como vimos com Mariani (1994), agora, anos 50, incorporados ao léxico: formas que o enriquecem. Se o índio é alçado à condição de elemento que contribui para a língua, acerca do elemento negro - os africanismos - não se pode dizer o mesmo. Mas os indianismos não compõem o campo de significância de brasileirismos na Revista Brasileira, ou seja, o índio continua autóctone. Contribui para a língua, não configura a língua.

Uma observação importante: a denominação brasileirismo não comparece em três dos artigos: estes tocam o "enriquecimento" e a "deturpação" da língua portuguesa, mas não se referem ao léxico com tal termo. É somente em "O português em Portugal e no Brasil: sobrevivência de palavras e construções” por Tenório d'Albuquerque que o termo se faz presente. Aí, não sem tensão, o termo compreende: arcaísmos e antigos vocábulos com novas significações (estes são denominados "brasileirismos semânticos"). Por "brasileirismos semânticos" entende-se um domínio de palavras correntes na língua portuguesa e que, em terras brasileiras, teriam outros sentidos.

"Fizemos, na parte anterior, comentário acerca de alguns vocábulos que, em Portugal, tem sentido diferentes.

Talvez pudéssemos classificar essas mudanças do sentido, no Brasil, de brasileirismo semântico. (TENÓRIO D’ALBUQUERQUE, 1960, p. 149-150) (itálico do autor)

Ou seja, sob as mesmas palavras se encontrariam outros sentidos. Os brasileirismos são... semânticos. Não se sai, então, do léxico português. Sai-se, 
somente, e em decorrência da mudança geográfica, como já observamos, de um território. Sai-se dos sentidos.

São nos arcaísmos que a tensão da denominação "brasileirismo" se instaura. Um dos artigos da revista se detém sobre inúmeros casos considerados como brasileirismos que constituiriam arcaísmos portugueses que sobreviveriam no Brasil. Observe-se:

“(...) e tantos outros, escreveram para demonstrar que muitos brasileirismos, por vezes repelidos, não passam de construções ou vocábulo agora em desuso em Portugal, que são conservados no Brasil.

No interior do Brasil, persistem certos modismos, construções e vocábulos que vamos encontrar em escritores portugueses de dois ou três séculos." (TENÓRIO D’ALBUQUERQUE, 1960, p. 134) ${ }^{12}$ (negrito meu)

Ou seja, brasileirismos não são brasileirismos, são arcaísmos, formas outrora usadas na língua portuguesa. São inúmeros os casos registrados - o artigo é longo e compreende uma listagem de palavras e expressões - em que se recupera na língua portuguesa um uso anterior àquele verificado no Brasil. Vejamos algumas seqüências:

“Gainhar, forma corrente entre os nossos matutos, é arcaica." (TENÓRIO D’ALBUQUERQUE, 1960, p. 142) (itálico do autor)

"O adjetivo fermoso, tão encontradiço no linguajar dos nossos sertanejos, é sobrevivência da forma arcaica portuguesa, usada pelos clássicos quinhentistas." (idem, p. 137) (itálico do autor)

"O advérbio despois, de tão farto emprego das pessoas incultas do interior é outra forma desusada em Portugal, que se conserva no Brasil.

Repetidas vezes, Camões empregou a forma despois. (idem, p. 138) (itálico do autor)

Aponta-se ainda o engano de autores que citaram casos de brasileirismo:

\footnotetext{
${ }^{12} \mathrm{Em}$ que as reticências iniciais dizem respeito às inúmeras referências feitas a autores e livros que trataram da questão dos brasileirismos.
} 
"Figueiredo averbou como brasileirismo do sul a palavra folheiro, vistoso, por não conhecer esse passo de D. Francisco Manuel de Melo: 'Respondeu: amiga aquêles cavalos suposto que tão folheyros, são muito fracos..." (...) (idem, p. 141) (itálico do autor)

Mais uma vez não se sai da língua portuguesa. Os supostos brasileirismos já existiam na língua portuguesa. São arcaísmos. É interessante notar que é a língua portuguesa, o idioma, que irá legitimar o que aqui ocorre, seja na fala culta seja na fala inculta, seja o acerto, seja o erro, em qualquer modalidade:

“Tá por está. Em linguagem descuidada, ouve-se com freqüência, no Brasil, a deturpação tá por está.

Exemplo: 'Quem está aí? Ou Quem taí?'

'Na linguagem popular é freqüente ouvir-se na segunda e terceira pessoa do singular do presente do indicativo tás e tá, em vez de estás e tá. (Compêndio da Gramática Histórica Portuguesa, 306, Livraria Clássica Editora, Lisboa, 1919)

Como se vê não se trata de deturpação peculiar ao Brasil. O fenômeno ocorre, também, em Portugal, mas como se trata de deformação foi precipitadamente classificada de... brasileirismo." (idem, p. 144) (itálico do autor)

Ou seja, o idioma português legitima a língua que comparece em solo brasileiro. Os brasileirismos resultam em construções já existentes em língua portuguesa, e, mesmo quando há brechas, observe-se a seqüência a seguir,

"Muitos brasileirismos há, até, com raízes latinas. Vezes há, é certo, que a palavra não pertence à língua comum de além-mar, nem mesmo está documentada nos textos; mas deve ter existido no passado, ou viçar ainda nalgum recanto. (idem, p. 141) (itálico do autor e negrito meu)

estas são costuradas de maneira a apagar a possibilidade de brasileirismo: não só o latim a confirma como a língua portuguesa (deve ter existido no passado) também.

Na Revista Brasileira o léxico comparece, como já dito, como espaço do erro e do acerto, na língua falada e na língua escrita culta e inculta. Se é espaço da especificidade, é espaço que resulta no mesmo: recupera um 
léxico perdido e/ou esquecido, dá novos sentidos - "novo fôlego" para usar a metáfora com que Tenório d'Albuquerque recuperando um português, Vasco Botelho do Amaral, encerra seu texto - e assim contribui com o idioma português. Não se sai da formação discursiva que postula um idioma nacional. A especificidade garante a unidade.

\section{Palavras que fecham}

$\mathrm{Na}$ Revista brasileira, ao se dizer da língua que aqui comparece, trabalha-se identidade brasileira, afirmando-a por meio da portuguesa. A ilusão é a de igualar brasileiros e portugueses. Aqueles nos deram a língua, nós contribuímos e a enriquecemos. Se erramos, a própria língua permite. Quando não permite, é o caso de rejeitar e censurar. Se erramos, os portugueses também erram e também precisam ser corrigidos. E podemos fazê-lo, isto é, já temos autoridade para corrigi-lo. A língua estaria acima dos espaços geográficos. Isto significa ser na matriz nacionalista: defender a língua de quem a deturpa. Em outras palavras, a nacionalidade se inscreve na diferença, na especificidade, mas o que a garante é a filiação a Portugal, ao idioma português. O nacional, o brasileiro, é aí acréscimo no mesmo.

\section{Referências Bibliográficas}

AUROUX, Sylvain. A revolução tecnológica da gramatização, Campinas, São Paulo: Unicamp, 1992.

COUTINHO, A. e GALANTE DE SOUZA, J. (dir.). Enciclopédia de Literatura brasileira. São Paulo: Global, Fundação Biblioteca Nacional/ DNL, Academia Brasileira de Letras, 2001.

DIAS, Luiz Francisco. "O nome da língua no Brasil: uma questão polêmica", in: ORLANDI, E. (org.), História das idéias políticas: construção do saber metalingüístico e constituição de língua nacional. Campinas, São Paulo: Pontes; Cáceres, Mato Grosso: UNEMAT, 2001.

NEVES, Fernão. A Academia Brasileira de Letras: notas e documentos para sua história (1896-1940). Rio de Janeiro: ABL, 1940.

GUIMARÃES, Eduardo. "Sinopse dos Estudos do Português do Brasil: a Gramatização Brasileira”, in: GUIMARÃES, Eduardo e ORLANDI, Eni (orgs.) Língua e cidadania: o português no Brasil. Campinas, São Paulo: Pontes, 1996. 
HENRIQUES, Claudio. Cezar. Atas da Academia Brasileira de Letras: Presidência Machado de Assis (189601908). Rio de Janeiro: Academia Brasileira de Letras, 2001.

MARIANI, Bethania."1822, Pátria independente: outras palavras?", in: Revista Organon, no. 21, vol. 8, 167 páginas, Porto Alegre: Universidade Federal do Rio grande do Sul, 1994.

. "Colonização lingüística e efeitos de memória”, Revista Língua e instrumentos lingüísticos, no. 16, 95 páginas, Campinas, São Paulo: Unicamp, 2006.

. Colonização lingüística, Campinas, São Paulo: Pontes, 2004.

MARIANI, Bethania e MEDEIROS, Vanise. "Notícias de duas pesquisas: idéias lingüísticas e governo JK", Revista Desenredo: Revista do programa de Pós-Graduação em Letras da Universidade de Passo Fundo. Passo Fundo, RS: Universidade Passo Fundo, 2006.

MEDEIROS, Vanise. Dizer a si através do outro: do heterogêneo no identitário brasileiro. Tese de doutorado, UFF, 2003.

NOGUEIRA, Julio. "Em defesa da língua”, Revista Brasileira, ano iX, vol. 23-24, julho-dezembro de 1958. Rio de Janeiro: Academia Brasileira de Letras, 1959.

"A Língua Falada", Revista Brasileira, ano X, vol. 27, julho-dezembro de 1959. Rio de Janeiro: Academia Brasileira de Letras, 1960.

“Notícias” Revista Brasileira, ano IX, vol.21-22, janeiro-junho de 1958, Rio de Janeiro. Academia brasileira de Letras, 1959.

NUNES, José Horta (2005). “As palavras, o espaço e a língua: o vocabulário pernambucano", Revista Língua e instrumentos lingüísticos, no. 16, 95 páginas. Universidade Estadual de Campinas: Pontes; Campinas, São Paulo: Unicamp, 2005.

ORLANDI, Eni. Terra à vista! discurso do confronto: velho e novo mundo, São Paulo: Cortez. Campinas, São Paulo: Unicamp, 1990.

. As Formas do silêncio: no movimento dos sentidos. Campinas, São Paulo: Editora da UNICAMP, 4a . ed., 1997.

. “O discurso sobre a língua no período Vargas (Estado Novo - 1937/1945)”, Língua e instrumentos lingüísticos, no. 15, 87 páginas, 2005. 
. Língua e conhecimento lingüistico: para uma história das idéias no Brasil. São Paulo: Cortez, 2002.

PÊCHEUX, Michel. Semântica e discurso. Campinas, São Paulo: UNICAMP, 1988.

PFEIFFER, Claudia, "A língua nacional no espaço das polêmicas do século XIX/XX”, Orlandi, E. (org.), História das idéias políticas: construção do saber metalingüístico e constituição de língua nacional. Campinas, São Paulo: Pontes; Cáceres, Mato Grosso: UNEMAT, 2001.

TENÓRIO D’ALBUQUERQUE. “Novos idiomas? Não!”, Revista Brasileira, ano IX, vol. 25-26, janeiro-junho de 1959. Rio de Janeiro: Academia Brasileira de Letras, 1959.

TENÓRIO D’ALBUQUERQUE. “O português em Portugal e no Brasil: sobrevivência de palavras e construções” Revista Brasileira, ano X, vol. 27, julho-dezembro de 1959. Rio de Janeiro: Academia Brasileira de Letras, 1960. 